\title{
Advanced Solid State Sensors for Vision 21 Systems $1^{\text {st }}$ Annual Report
}

Contract No. DEFG2601NT41273

Reporting Period

September 11, 2001 - September 12, 2002

\author{
Prepared For \\ National Energy Technology Laboratory \\ Morgantown, WV
}

\author{
Prepared By ${ }^{1}$ K. Meehan, and ${ }^{2}$ C.D. Stinespring \\ ${ }^{1}$ Bradley Department of Electrical and Computer Engineering, Virginia Tech \\ ${ }^{2}$ Department of Chemical Engineering, West Virginia University
}

February 12, 2003 


\section{DISCLAIMER}

This report was prepared as an account of work sponsored by an agency of the United States Government. Neither the United States Government nor any agency thereof, nor any of their employees, makes any warranty, express or implied, or assumes any legal liability or responsibility for the accuracy, completeness, or usefulness of any information, apparatus, product, or process disclosed, or represents that its use would not infringe privately owned rights. Reference herein to any specific commercial product, process, or service by trade name, trademark, manufacturer, or otherwise, does not necessarily constitute or imply its endorsement, recommendation, or favoring by the United States Government or any agency thereof. The views and opinions of authors expressed herein do not necessarily state or reflect those of the United States Government or any agency thereof. 


\begin{abstract}
Device fabrication and characterization studies relevant to the development of silicon carbide (SiC) based gas and temperature sensors have been performed. Initial studies of Pd deposition on Si were performed since the procedures for Si substrate preparation were well known to us. This allowed us to gain experience in controlling the deposition process while continuing to investigate methods of preparing the $\mathrm{SiC}$ substrate surface. Studies of SiC surface preparation were carried out under a separate contract. As our SiC substrate preparation techniques improved, studies of Pd deposition on $\mathrm{SiC}$ were performed and the thermal stability of $\mathrm{Pd} / \mathrm{SiC}$ interfaces (i.e., the critical sensor component) was characterized. These studies have demonstrated that the $\mathrm{Pd} / \mathrm{SiC}$ interface is remarkably stable at temperatures up to $670{ }^{\circ} \mathrm{C}$. At this time, we are moving rapidly to a point where the oxide overlayer can be reproducibly reduced to an acceptable level and large areas of the substrate can be reproducibly produced with the surface roughness reduced to the atomic scale. We believe that this will substantially improve the thermal stability of the $\mathrm{Pd} / \mathrm{SiC}$ interface. In all these studies, techniques are being used that could readily be incorporated into commercial processes. Moreover, as a result of our ultrahigh vacuum approach to device fabrication, we are in a position to monitor and document each step of the process and to relate this data to device characteristics and performance. Experiments are now underway to study the effects of improved substrate surfaces on these interfaces. Device modeling and electrical characterization studies were performed to complement the device fabrication studies. These included temperature dependent I-V and series resistance measurements for SiC p-n junctions. Presently, $\mathrm{Pd} / \mathrm{SiC}$ structures produced in the above deposition experiments are undergoing electrical characterization.
\end{abstract}




\section{CONTENTS}

ABSTRACT $\ldots \ldots \ldots \ldots \ldots \ldots \ldots \ldots \ldots \ldots \ldots \ldots \ldots \ldots \ldots \ldots \ldots \ldots \ldots \ldots \ldots$

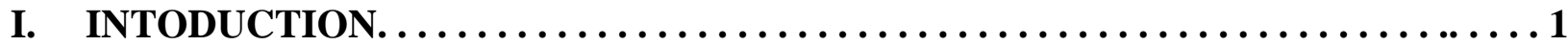

a) Vision 21 and Silicon Carbide Sensor Technology $\ldots \ldots \ldots \ldots \ldots \ldots \ldots \ldots \ldots 1$

b) Silicon Carbide Sensor Research at West Virginia University $\ldots \ldots \ldots \ldots \ldots \ldots$

II. EXPERIMENTAL $\ldots \ldots \ldots \ldots \ldots \ldots \ldots \ldots \ldots \ldots \ldots \ldots \ldots \ldots \ldots \ldots$

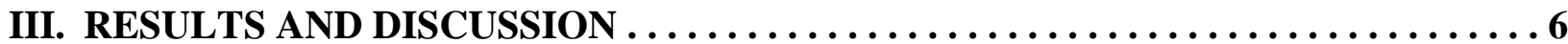

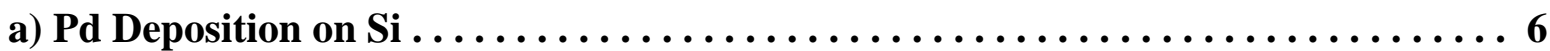

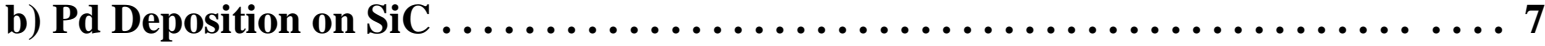

c) Modeling and Electrical Characterization of $\operatorname{SiC}$ p-n Junctions. . . . . . . . . 8

IV. CONCLUSIONS AND FUTURE WORK $\ldots \ldots \ldots \ldots \ldots \ldots \ldots \ldots \ldots \ldots$

V. REFERENCES ................................ 11 


\section{Advanced Solid State Sensors for Vision 21 Systems I, INTRODUCTION}

a) Vision 21 \& Silicon Carbide Sensor Technology

Vision 21 power plants such as that illustrated in Figure 1 are envisioned as highly integrated, advanced technology modules operating at high efficiency with essentially zero environmental impact. Candidate technologies that may be utilized in Vision 21 systems include advanced coal gasification and combustion processes combined with turbines or fuel cells. To realize this goal, sophisticated computer algorithms must control the plant with sensors providing the real time plantcomputer interface.

At the present time, this vision is well beyond the state-of-the-art capability for sensors and control systems presently used in any industry. In particular, measurements of two of

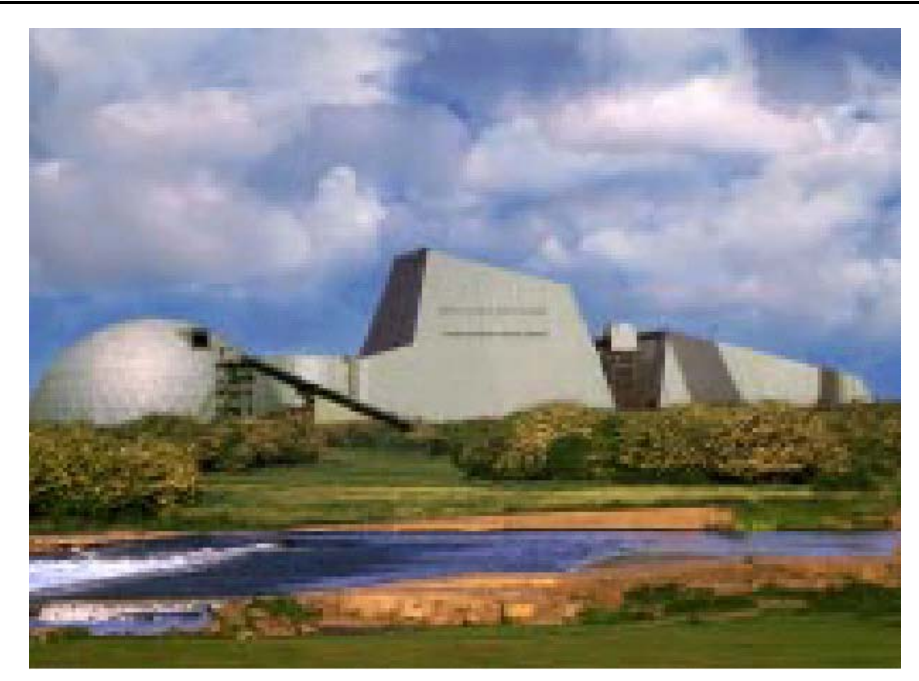

Figure 1. Artist rendition of Vision 21 plant. [From Vision 21 Technology Roadmap.]

the most important process parameters, gas species concentrations and gas / component temperatures, are extremely challenging at the high temperatures found in the anticipated coalenergy conversion processes that will be used in Vision 21 power plants. In fact, there has been debate over just what the upper limit of most desirable or useful process temperature range should be. Likewise there is some uncertainty as to the gas species of interest. Although a few very likely candidates can be readily identified.

Despite these challenging conditions and uncertainties, emerging sensor technologies do exist with the capability of performing the desired measurements. One of the most promising of these is based on presently emerging silicon carbide ( $\mathrm{SiC}$ ) technology.

$\mathrm{SiC}$ is wide band gap semiconductor that has exceptional high temperature properties and stability. SiC has two primary crystal forms, the cubic structure which has one polytype ( $\beta$-SiC) and the hexagonal which has numerous polytypes (e.g., 4H- and 6H-SiC). Free standing, 2-inch diameter hexagonal type wafers of increasingly high quality are readily available today. These are grown by high temperature chemical vapor transport methods. Most cubic material is grown as thick films on commercial silicon (Si) substrates using chemical vapor deposition methods. The availability of high quality $4 \mathrm{H}$ - and $6 \mathrm{H}$-SiC wafers represents a tremendous technology investment in hexagonal $\mathrm{SiC}$ wafer development by the Federal Government over the past 15 to 20 years.

The use of SiC as a high temperature electronics material has been the subject of study for many years.[1] Moreover, proof of principle measurements have been performed which demonstrate the materials potential for gas species measurements. One example of these is given in Figure 2 which shows $\mathrm{CO}$ measurements performed using a $\mathrm{SiC}$ sensor operating at $275{ }^{\circ} \mathrm{C}$ (left axis) and Fourier transformed infrared (FTIR) spectroscopy as a control (right axis) 
measurement.[2] Similar measurements have been obtained for $\mathrm{H}_{2}, \mathrm{NH}_{3}, \mathrm{O}_{2}, \mathrm{NO}, \mathrm{CO}, \mathrm{SO}_{2}$, and $\mathrm{CH}_{4} \cdot[3,4]$

Present limitations on the use of $\mathrm{SiC}$ technology under harsh conditions are not due to the inherent materials properties of $\mathrm{SiC}$ but to thermal instability of the sensor structure and quite possibly to defects produced in the processing and finishing (chemo-mechanical polishing) of the $\mathrm{SiC}$ wafers themselves. To understand the origins of these limitations, it is helpful to have an understanding of the structure and operation of the devices themselves.

An example of a metal-insulator-SiC (MISiC) type sensor structure is illustrated in Figure 3. It consists of thin $\mathrm{SiO}_{2}$ and metal films deposited on a p-n junction. The junction itself is formed by the deposition of a thin n-type epitaxial $\mathrm{SiC}$ layer on a commercially available n-type $4 \mathrm{H}$ - or $6 \mathrm{H}$-SiC substrate. The thickness of this epi-layer is in the range of $1-10 \mu \mathrm{m}$. Frequently referred to as the catalyst, typical metals used in sensor structures include Pt, Ir, and Pd.

In operation, target molecules such as $\mathrm{H}_{2}$ react with the metal surface to produce steady state concentration of surface intermediates. Due to charge transfer between the intermediates and the surface these species can be polarized, and the resulting polarization field shifts the electrical properties of the p-n junction.

The property of these structures that makes these useful as sensors is the fact that the shift in electrical characteristics is dependent on the target species as illustrated in Figure 4. Here the shift in turn-on voltage for the p-n junction is shown for two different gases, $\mathrm{H}_{2}$ and $\mathrm{O}_{2}$.

The problem that arises is that over long term operation at high temperatures,[5] the sensitivity of the sensors degrades. Early sensors were simple Schottky diodes composed of a metal deposited directly on the SiC. It was observed, however, that annealing the devices for 140 hours at $425{ }^{\circ} \mathrm{C}$ reduced their sensitivity.[6] Careful studies of the metalsemiconductor interface revealed that this was

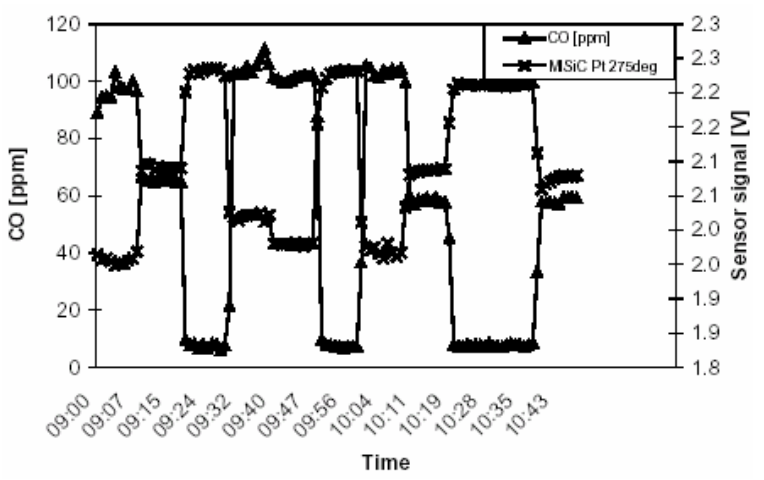

Figure 2. Experimental measurements of $\mathrm{CO}$ concentration versus time measured a $\mathrm{SiC}$ sensor operation at $275{ }^{\circ} \mathrm{C}$. [From Spetz, et al., Proc. Transducers'99, Sendai, Japan, (1999) 946-949.]

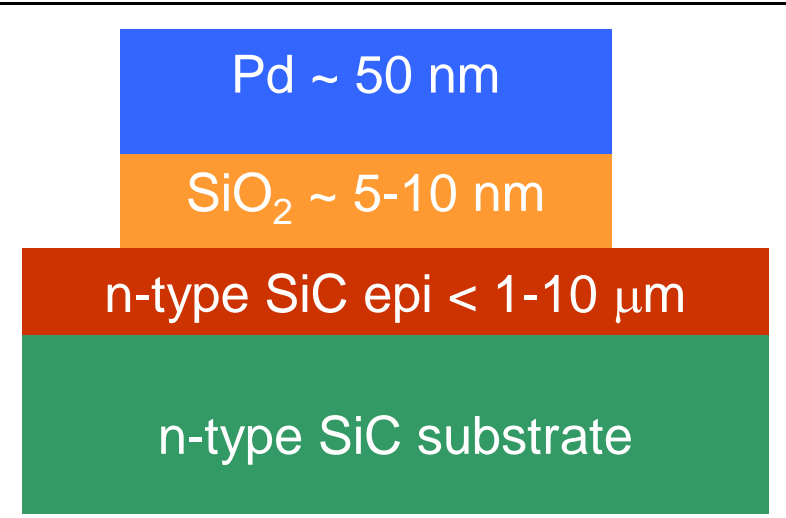

Figure 3. Schematic of MISiC type sensor structure used for gas and temperature sensing applications in harsh environments.

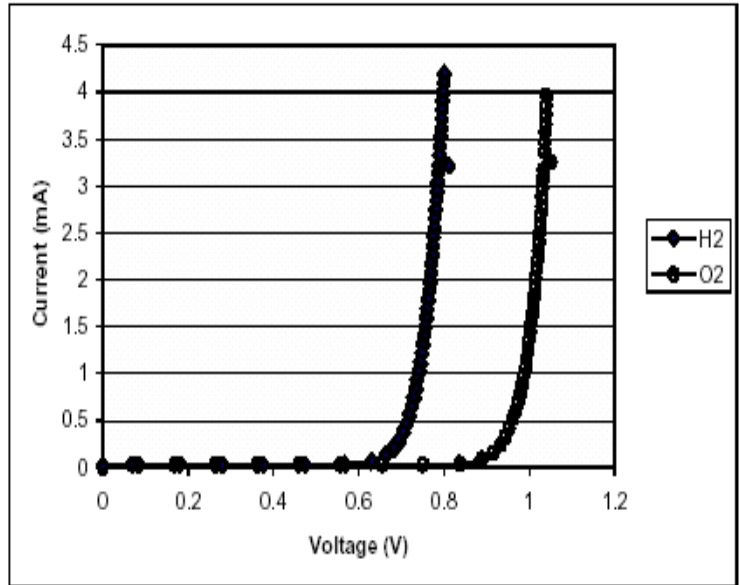

Figure 4. From Spetz, et al, Proc. Transducers'99, Sendai, Japan, June 7-10 (1999) 946-949. 
due to interfacial reactions that produced various metal silicides and graphite. The device structure shown in Figure 3 was designed to circumvent this limitation. The oxide layer was inserted to decrease the extent of interfacial diffusion and reaction between the metal and the substrate. Although the oxide layer stabilized the interface, the sensitivity rapidly decreased due to the formation of an $\mathrm{SiO}_{\mathrm{x}}$ layer on the metal surface. This was thought to be due to the reduction in active gas dissociation sites on the metal and the formation of an electronic barrier.

A further limitation of these sensors is that the device response is a function of temperature. As a result, it will be necessary in actual sensor applications to know the temperature at the location of the sensor.

\section{b) Silicon Carbide Sensor Research at West Virginia University}

The overall SiC research program at West Virginia University is aimed resolving several key issues relating to device design and fabrication that currently limit existing SiC devices. Specifically these include:

a) Stabilization of the catalyst-SiC interface in Schottky diode type sensors using a thermally stable metal silicide layer between the catalyst and the SiC substrate.

b) Preparation of damage free $\mathrm{SiC}$ wafer surfaces using high temperature $\mathrm{H}_{2}$ etching.

c) Deposition of epitaxial SiC films and overlayers.

The present DOE program is primarily focused on the first of these issues. Moreover, it is our goal to fabricate a stable, integrated gas and temperature sensor, thereby allowing automatic temperature compensation of the device.

The approach adopted in our studies is motivated by research performed in the early 1980's during the period when metal silicides were becoming an essential component of siliconmicroelectronics technology. In that work, the effort was directed at the formation of epitaxial silicides for use as ohmic or Schottky contacts and was driven by the need for improved performance resulting from stable, reproducible, crystalline interfaces.[7] In addition, these epilayers served as a stable template for subsequent $\mathrm{Si}$ and metal silicide epitaxy. At that time, metal silicide films were not adequate for their intended purpose. They were largely polycrystalline in nature, and, at best, it had been shown that epitaxial but faceted $\mathrm{NiSi}_{2}$ films could be grown on the Si (100) substrate.[8]

A major breakthrough was achieved in 1982 when it was shown that continuous planar single-crystal films of $\mathrm{NiSi}_{2}$ (<6 nm thick) could be grown on the $\mathrm{Si}(100)$ and (111) surfaces under ultrahigh vacuum (UHV) conditions.[9] The procedure involved nickel deposition on atomically clean $\mathrm{Si}$ at room temperature followed by low temperature annealing $\left(450{ }^{\circ} \mathrm{C}\right)$. This produced an epitaxial layer and depended critically on the thickness of the initial Ni layer. The thickness limits were 1.6 - $2.0 \mathrm{~nm}$ for the (111) surface and 1.0 - $3.0 \mathrm{~nm}$ for the (100) surface. Initial Ni film thickness less than or greater than these limits leads to mixed crystal phases and otherwise defective silicide films. Following the original work, we will refer to this as a thickness dependent phase transition in subsequent discussions. It was found that these silicide films were thermally stabilize and could be used as substrates for subsequent epitaxial thin film growth.[10]

The question central to the present DOE research is this: Does a similar thickness dependent phase transition exist for Pd, Pt, Ir, or possibly Ni films deposited on SiC surfaces? If the answer is yes, then silicide films formed from these metals may provide a thermally stable surface for the deposition of the metal catalyst layer required for simple Schottky barrier gas sensors. In addition, these stable silicide layers would also provide a more suitable surface for 
oxide deposition of MISiC type structures. Stated another way, a thickness dependent phase transition for any of these metals represents an important potential solution to the problem of long-term thermal degradation of the metal catalyst, in particular, and the overall gas sensor structure, in general.

Since beginning our research in October of 2001, it has become evident that high levels of damage in the surface and near surface layers of commercially available SiC substrates is another critical factor that may limiting the long-term thermal stability of both the Schottky and MISiC structures. The need for smooth, damage-free substrate surfaces prior to device processing steps such as epitaxial growth has long been understood as a critical requirement in silicon-microelectronics. There is no reason to believe that this is not also true for SiC based gas and temperature sensors such as those described here. When examined by a variety of nondestructive techniques, commercially available SiC wafers appear to have an excellent surface finish (i.e. average roughness less than $0.3 \mathrm{~nm}$ with no visible scratches).[11] However, $\underline{\mathbf{A L L}}$ commercially available wafer have varying levels of subsurface defects that are not benign with respect to device quality.

During the thin film deposition and growth processes associated with device fabrication, subsurface defects in the SiC substrate will propagate into the epitaxial layers degrading the device performance and reducing device yield.[12,13] In addition, electrically active near surface defects have also been observed.[14] The situation is such that surface and subsurface quality is often regarded as a limiting factor in the production of high quality SiC based devices.

As a result to these observations, we have begun a study under DARPA support to investigate a robust surface preparation process for consistent, damage-free SiC substrates. In as much as subsurface defects may themselves be the source of the thermal instability of sensor device structures, the current DOE research at WVU will incorporate the substrate preparation procedures developed under the DARPA program.

\section{EXPERIMENTAL}

The experimental work covered in this report includes experimental studies of $\mathrm{Pd}$ deposition on $\mathrm{Si}$ and $\mathrm{SiC}$, modeling studies of temperature dependent $\mathrm{p}$-n junction characteristics, and experimental measurements of $\mathrm{p}-\mathrm{n}$ junction characteristics. The substrates used in the Pd deposition studies were commercial n-type Si (001) (NOVA Electronic Materials, Inc.) and 6H-SiC (0001) (Sterling Semiconductor). The $\mathrm{p}-\mathrm{n}$ junctions were purchase form Boston Electric.

The gas source molecular beam epitaxy (GSMBE) system and surface characterization apparatus used in these studies is shown in Figure 5. The growth chamber is pumped by two turbo molecular pumps and operates at a base pressure of $5 \times 10^{-10}$ Torr. This sample manipulator allows precise positioning of the sample for both deposition and reflection high-energy electron diffraction (RHEED) analyses. In addition, the sample may be heated to temperatures on the order of $1000{ }^{\circ} \mathrm{C}$. The metal for the deposition studies was provided using an EPI-10HT high temperature effusion cell located in a water-cooled source ports. Additional gas sources are available which allow thin film growth using molecular and radical species. An Omega Model OS1562 fiber optic infrared sensor, also located on the source flange, was used for measuring substrate temperatures in the range of 400 to $1800{ }^{\circ} \mathrm{C}$ with an accuracy of $\pm 1 \%$. The size of the measurement spot at the substrate is $\sim 1 \mathrm{~mm}$ in diameter so that substrates may be readily temperature profiled. 
Once a deposition or growth sequence is completed, the sample may be transferred to the analysis chamber for characterization using Auger electron spectroscopy (AES). This chamber is pumped by a 220 $\mathrm{l} / \mathrm{s}$ ion pump and operates at a base pressure of $5 \times 10^{-10}$ Torr.

Both the $\mathrm{Si}$ and $\mathrm{SiC}$ substrates were prepared by a wet chemical etch procedure first developed by D.B. Fenner[15] and later modified by L.S. Hirsh in the Physics Department at WVU.[16] The effect of the "modified Fenner etch" on the surface chemistry of Si was more fully documented by K.S. Ziemer in this laboratory.[17] As demonstrated by reflection high energy electron diffraction (RHEED), low energy electron diffraction (LEED), and Auger electron spectroscopy (AES), the modified Fenner etch leaves the Si (001) surface in a H-terminated $1 \mathrm{x} 1$ surface reconstruction.

The conditions of the SiC substrate surface after the modified Fenner etch are under investigation at this time. We have seen that there is little difference between a simple HF dip $\left(1: 1 \mathrm{HF}: \mathrm{H}_{2} \mathrm{O}\right)$ and the more complex modified Fenner etch. In both cases, AES analyses indicate that much (although not all) of the native $\mathrm{SiO}_{\mathrm{x}}$ overlayer is removed, while RHEED analyses indicate that the surface is still disordered. In this respect, the oxide overlayer on $\mathrm{SiC}$ is much more tenacious than that found on $\mathrm{Si}$. Subsequent $\mathrm{H}_{2}$ etching of the $\mathrm{SiC}$ substrates is expected to produce atomically flat surfaces with characteristic step and terrace features. Experiments to demonstrate this are presently in progress, so to date, Pd deposition studies have been performed only on SiC substrates prepared by wet chemical etching.

The Pd source material used in the deposition studies was $99.99 \%$ pure Pd supplied by (Electronic Source Products). The deposition rate was determined by measuring substrate weight gain as a function of source temperature. The results of these measurements will be discussed in the next section. The overall deposition rate was controllable in the range of $0.5-5$ $\mathrm{ML} / \mathrm{min}$.

In addition to in-situ AES and RHEED studies, the substrates and Pd thin films were characterized using a number of ex-situ methods. These included atomic force microscopy (AFM) using a Joel Model 4210 located at the National Energy Technology laboratory, scanning electron microscopy (SEM), and optical microscopy.

The electrical characterization studies were carried out using facilities located at Virginia Tech. The measurements taken include series resistance and current-voltage (I-V) characteristics measured as a function of temperature. A Tektronics Type 576 curve tracer was used to collect the I-V data on SiC p-n diodes that were ramped from room temperature to $190^{\circ} \mathrm{C}$ in a Delta Design Model 2300 oven. Temperature was monitored using an Omega Type K thermocouple and HH506R hand-held meter. Preliminary modeling of the temperature sensitivity of the 
forward voltage and the reverse saturation current density of a SiC p-n diode was performed using a program developed by the present researchers in MathCAD 2001.

\section{RESULTS AND DISCUSSION}

a) Pd Deposition on Si

In these studies, H-terminated Si(100) 1x1 surfaces were prepared as described above and maintained $27{ }^{\circ} \mathrm{C}$, while Pd was deposited at a rate of 0.07 $\mathrm{nm} / \mathrm{min}$. Note that higher deposition rates are possible, but this rate was selected to allow precise control of the film thickness as well as studies of the very initial stages of the deposition process. At regular time intervals the deposition process was interrupted and the sample was analyzed using AES. Figure 8 shows a sequence of Si-LVV AES spectra obtained in this manner.

In Figure 6, the Si-LVV spectrum marked (a) is representative of the clean Si(100) 1x1. After $0.7 \mathrm{~nm}$ of Pd have

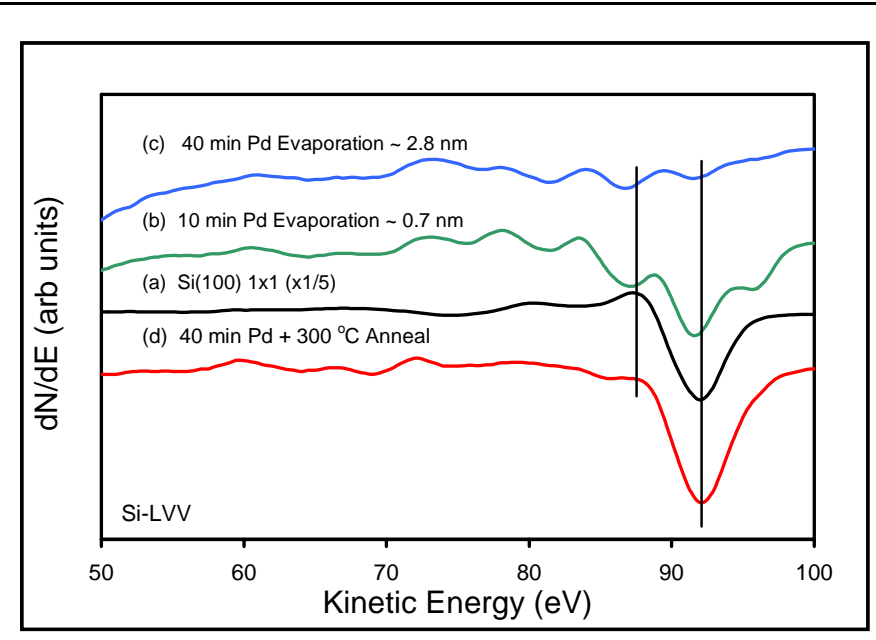

Figure 6. Si-LVV spectra for a) Si (100) 1x1 x1/5, b) after 0.7 $\mathrm{nm}$ of Pd have been deposited, c) after $2.8 \mathrm{~nm}$ of Pd have been deposited, and after annealing at $300{ }^{\circ} \mathrm{C}$ for 15 minutes. been deposited the spectrum marked (b) was obtained. If the Pd did not react with the Si in the substrate then this spectrum would have the same lineshape as that in (a), but the intensity would simply be attenuated by a factor of $\mathrm{e}^{-\mathrm{t} / \lambda}$. Here $\mathrm{t}$ is the thickness of the film $(0.7 \mathrm{~nm})$ and $\lambda$ is the mean free path of the Si-LVV electrons $(\sim 0.56 \mathrm{~nm})$. Clearly this is not the case. The lineshape has changed, and it is, in fact, characteristic of a $\mathrm{Pd}_{\mathrm{x}} \mathrm{Si}$ compound. That is, even at $27^{\circ} \mathrm{C}$ there is a reaction between the $\mathrm{Pd}$ and $\mathrm{Si}$.

With continued Pd deposition, the Si-LVV lineshape also continues to change as illustrated by the spectrum marked (c). In fact, it may also be observed by comparing spectra (b) and (c) that the relative intensities of the peaks making up the lineshapes are different. This has been studied previously and found to correspond to a change in stoichiometry of the $\mathrm{Pd}_{\mathrm{x}} \mathrm{Si}$ film with thickness. Figure 7 shows the spectrum marked b) above expanded to full scale with the intensities of the two major peaks indicated by "c" and “d”. Based on work by Bermudez,[18] the relative intensities of these peaks (as shown by the inset) can be used to establish the value of $x$ in $\mathrm{Pd}_{\mathrm{x}} \mathrm{Si}$. From our observations, the $\mathrm{Pd}$ film evolves from $\mathrm{Pd}_{3} \mathrm{Si}$ to $\mathrm{Pd}_{4} \mathrm{Si}$ finally to $\mathrm{Pd}$ as the film increases in thickness. This indicates a significant level of Pd and Si interdiffusion.

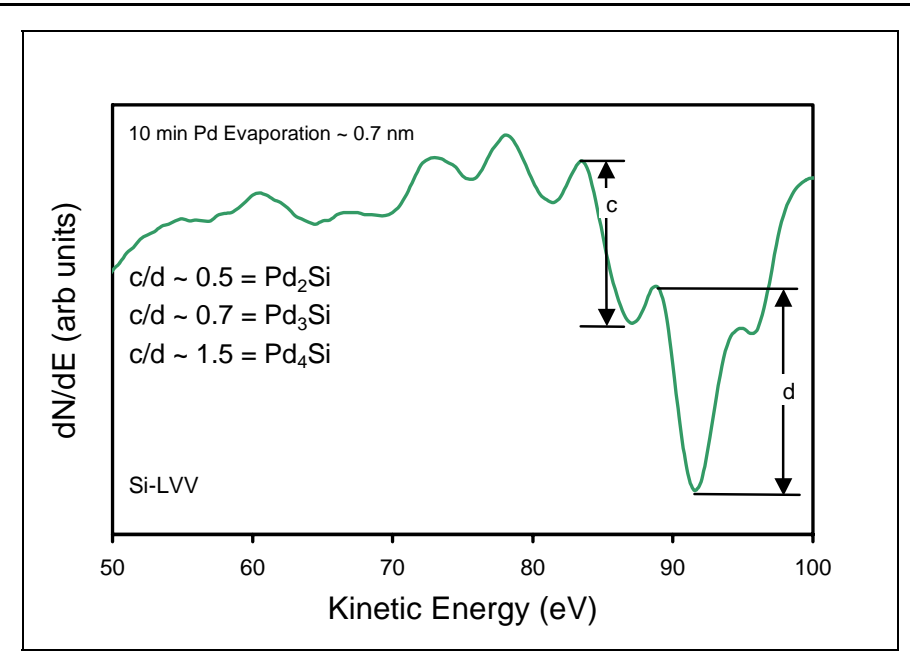

Figure 7. Si-LVV AES lineshape for PdxSi with $\mathrm{x} \sim 3$. 
It is remarkable that even at $27{ }^{\circ} \mathrm{C}$ there is such significant interdiffusion and reaction of the Si and Pd. Moreover, after annealing the film at $300{ }^{\circ} \mathrm{C}$ for 15 minutes, most of the lineshape and intensity of un-reacted Si (i.e., elemental $\mathrm{Si}$ ) is observed. This suggests significant in-diffusion of $\mathrm{Pd}$, out-diffusion of $\mathrm{Si}$, or coalescence of a relatively uniform (laterally) $\mathrm{Pd}_{\mathrm{x}} \mathrm{Si}$ film into small two- or threedimensional (2-D or 3-D) clusters.

Figure 8 shows a $\sim 5 \times 5 \mu \mathrm{m}$ square area representative of the annealed surface. The white line shows the position corresponding to the elevation or "line" profile illustrated in Figure 9. The $5 \times 5 \mu \mathrm{m}$ area shows a number of bright spots on a relatively uniform, dark background. The bright spots correspond to hillocks, and the brighter the spot the higher the hillock. Overall, the $5 \times 5 \mu \mathrm{m}$ area has a root mean square (rms) surface roughness of 1.25 $\mathrm{nm}$. The rms value for the line is $1.30 \mathrm{~nm}$, which indicates that the line profile is roughly typical of the entire area. Noting the large difference in magnification of the elevation ( 1000) relative to the lateral scale, the annealed surfaces are relatively flat with 2-10 nm scale hillocks.

The AFM and AES data both suggest that the initially uniform, $2.8 \mathrm{~nm}$ thick $\mathrm{Pd}_{\mathrm{x}} \mathrm{Si}$ film coalesces into 3D clusters. This would be consistent with previous observations by Poate and co-workers[9,10] for "thick" $\mathrm{Ni}$ films deposited on $\mathrm{Si}$. These results suggest the that future studies of Pd deposition on Si should focus on thinner initial layers in order to establish the conditions for the thickness dependent phase transition to thermally stable $\mathrm{Pd}_{\mathrm{x}}$ Si films.

\section{b) Pd Deposition on SiC}

In these studies, the SiC surface was prepared by an HF acid dip and modified Fenner etch as described previously. This represents an intermediate state in our ability to clean the SiC substrate surface and remove surface scratches and associated sub-surface damage as well as the oxide overlayer. The Si-LVV lineshape associated with such a surface is illustrated by the

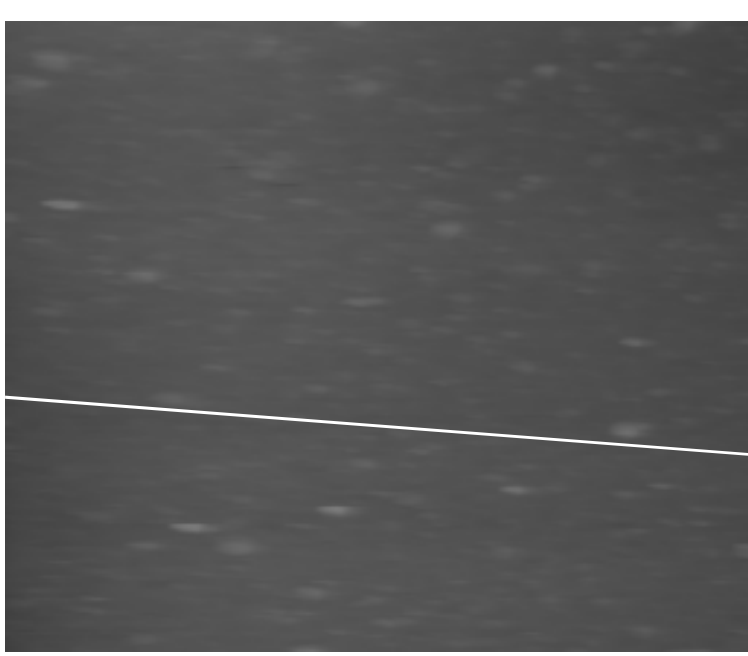

Figure 8. AFM image of $\mathrm{Pd}_{\mathrm{x}} \mathrm{Si}$ film after annealing at $300{ }^{\circ} \mathrm{C}$.

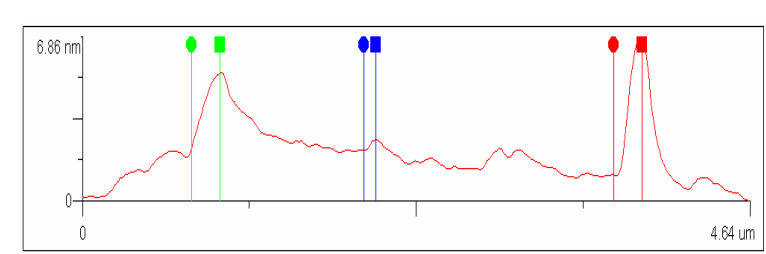

Figure 9. Elevation profile corresponding to the white line in Figure 8.

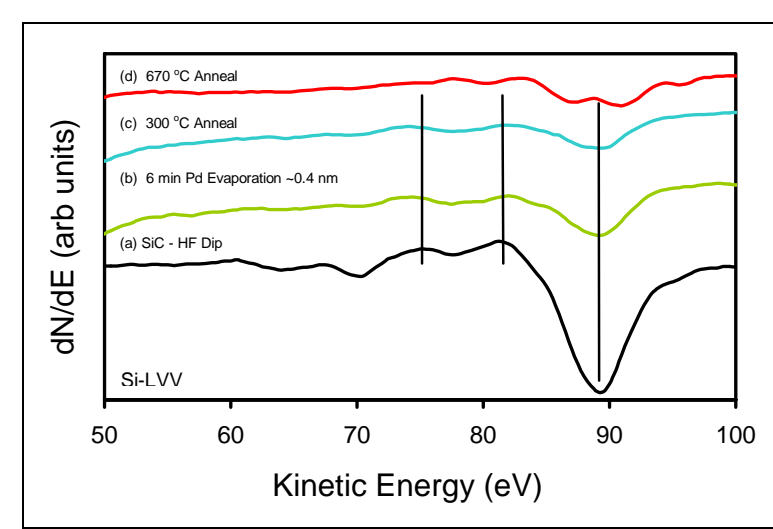

Figure 10. Si-LVV spectra for a) SiC, b) $0.4 \mathrm{~nm}$ of $\mathrm{Pd}$ deposited on SiC, c) after annealing at $300^{\circ} \mathrm{C}$ for 15 minutes, and d) after annealing at $670^{\circ} \mathrm{C}$ for 15 minutes. 
spectrum marked (a) in Figure 10. [Note also the differences between the Si-LVV lineshape for clean Si (Figure 7-a) and SiC (Figure 10-1).] After deposition of $0.4 \mathrm{~nm}$ of Pd on this surface while maintaining the substrate at $27{ }^{\circ} \mathrm{C}$, the spectrum marked (b) was obtained. It is clear that the only effect of the Pd overlayer is to reduce the intensity of the substrate Si-LVV peak, but the lineshape remains unchanged. Thus in contrast to the case for $\mathrm{Si}$, there is no reaction and no interdiffusion when $\mathrm{Pd}$ is deposited on $\mathrm{SiC}$ at $27{ }^{\circ} \mathrm{C}$. That is the mobility of the reactants is very much less for $\mathrm{SiC}$ as compared to $\mathrm{Si}$.

As seen in the spectrum marked (c), there is still no evidence of a reaction between Pd and Si after annealing the Pd film at $300{ }^{\circ} \mathrm{C}$. This contrasts markedly with the high reactivity and mobility of Pd and Si for the Si substrate. As seen in the spectrum marked (d), no significant reaction between $\mathrm{Pd}$ and $\mathrm{Si}$ is observed until the sample is annealed at $670{ }^{\circ} \mathrm{C}$. This is a very positive sign with regard to the prospects for preparing thermally stable silicide overlayers for gas and temperature sensor structures.

\section{c) Modeling and Electrical Characterization of SiC p-n Junctions}

The measurable p-n junction characteristics include the reverse saturation current and the built-in voltage for temperature measurements, while changes in I-V characteristics are most useful for gas sensing applications. We have modeled the dependence of both the reverse saturation current and the built-in voltage as a function of temperature for reasonable choices of doping levels, and the results suggest that the reverse saturation current is too low for practical measurements, but built-in voltage is readily measurable. The reverse saturation current density was in the nanoampere range, even at the elevated temperatures found near combustion furnaces, for reasonably sized devices. Thus, the cost of a temperature sensor based upon the measurement of the reverse saturation current would be driven by the need to use expensive ammeters and techniques to minimize noise generation.

From the modeling results, the change in the forward voltage at a specified current was found, as expected, to be dependent on the doping concentration of the p- and n-type regions near the diode junction. The larger the product of the carrier concentration in the n-type and ptype regions is, the larger the voltage is at a specific current as shown in Figure 11. However, the magnitude of the change in the forward
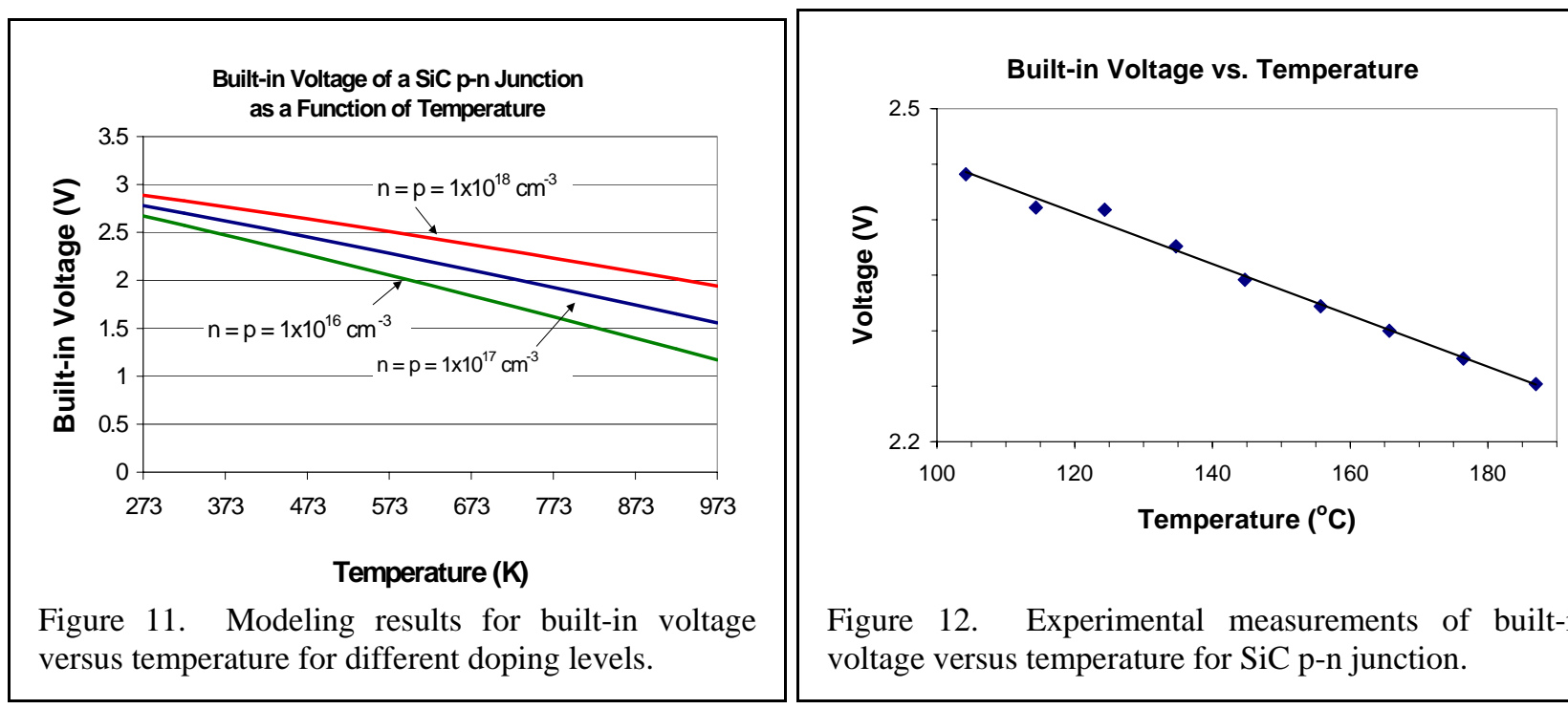

Figure 12. Experimental measurements of built-in voltage versus temperature for $\mathrm{SiC}$ p-n junction. 
voltage as a function of temperature is smaller as this product increases. Due to limitations imposed upon the maximum temperature of operation of the diode as a result of the increase in the intrinsic carrier concentration as a function of temperature, the minimum dopant concentration for either the n-type or p-type regions was constrained to be greater than $10^{15} \mathrm{~cm}^{-3}$. Thus, the calculated change in voltage as a function of temperature, $\mathrm{dV} / \mathrm{dT}$, for a SiC diode ranges between $-2.5 \mathrm{mV} /{ }^{\circ} \mathrm{C}$ for lightly doped diodes to $-1.2 \mathrm{mV} /{ }^{\circ} \mathrm{C}$ for heavily doped diodes.

Experimental measurements on commercially available $\mathrm{SiC}$ diodes confirmed the theoretical calculations (see Figure 12). dV/dT was found to be $-2.5 \mathrm{mV} /{ }^{\circ} \mathrm{C}$. The $\mathrm{dV} / \mathrm{dT}$ found is of the same magnitude as that found for Si diodes, which are extensively used to monitor low temperatures. Therefore, we are confident that SiC diodes may be used as temperature sensors for Vision 21.

The series resistance of the diodes was also calculated as a function of temperature from the set of I-V data taken (see Figure 13). This measurement indicates that there is an incomplete activation of the impurities at room temperature. This would imply that measurements of the device properties should not be taken at room temperature and then extrapolated to predict

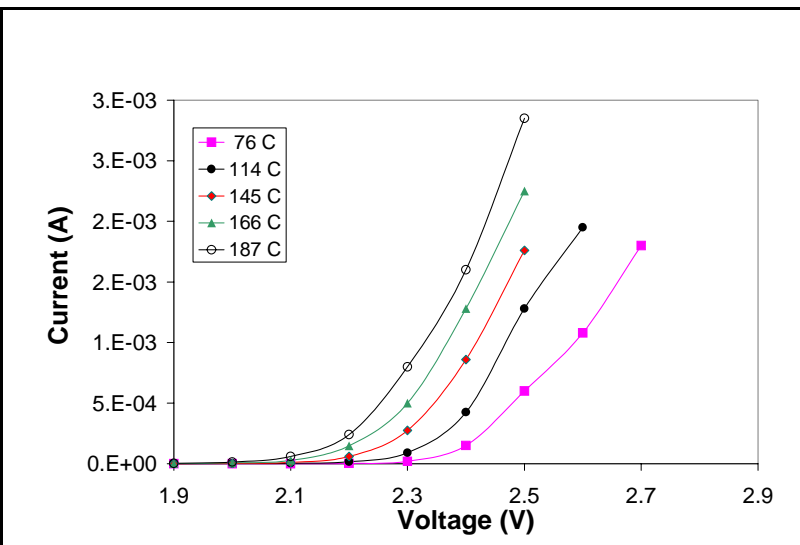

Figure 13. I-V data for $\mathrm{SiC} p-n$ junction for temperatures in the range of $70{ }^{\circ} \mathrm{C}-187^{\circ} \mathrm{C}$.

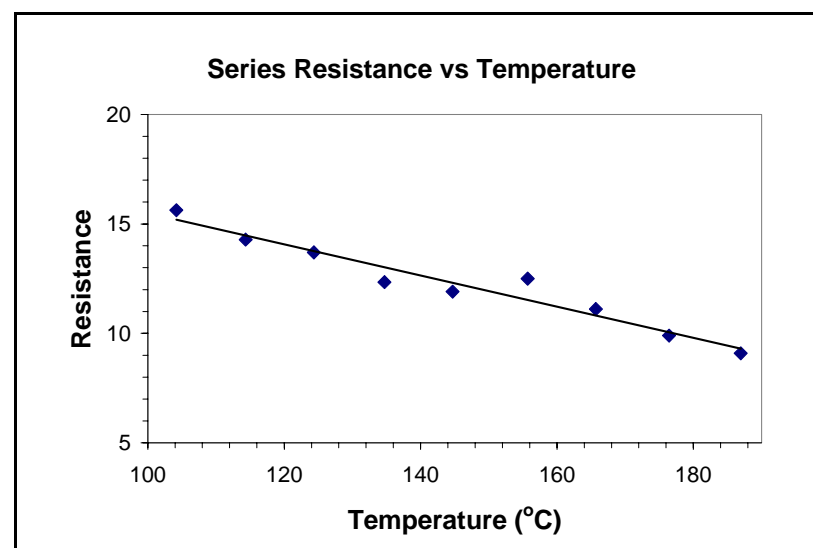

Figure 14. Series resistance of $\mathrm{SiC}$ p-n junction as a function of temperature.

device properties at high temperatures $\left(600^{\circ} \mathrm{C}\right.$ or greater)d. Rather, the device properties should be measured at a slightly elevated temperature of at least $90^{\circ} \mathrm{C}$ to properly characterize these devices, as shown in Figure 14.

\section{CONCLUSIONS AND FUTURE WORK}

In the first year of this program, we have performed device fabrication and characterization experiments to further define and extend the scope of this research. Specifically we began with studies of Pd deposition on Si since the procedures for Si substrate preparation were well known to us. This allowed us to gain experience in controlling the deposition process while continuing to investigate methods of preparing the SiC substrate surface. The preparation of the $\mathrm{SiC}$ surface for the hexagonal types of $\mathrm{SiC}$ available as commercial wafers is an area that has never been successfully addressed. Based on our results, we believe that measured properties of $\mathrm{SiC}$ devices based on these materials have all incorporated, at a minimum, the effects of surface and subsurface mechanical damage due to cutting and polishing as well as the effects of a tenacious oxide that is more difficult to remove than that found on commercial Si 
substrates. The point being made here is that all of these difficulties could easily contribute to the observed performance degradation and thermal instability of $\mathrm{SiC}$ gas sensors over long periods of operation.

As SiC substrate preparation techniques improved, the deposition or $\mathrm{Pd}$ on SiC was investigated and the thermal stability of $\mathrm{Pd} / \mathrm{SiC}$ interfaces (i.e., the critical sensor component) was characterized. At this time, we are moving rapidly to a point where the oxide overlayer can be reproducibly reduced to an acceptable level and large areas of the substrate can be reproducibly produced with the surface roughness reduced to the atomic scale. We believe this will lead to substantial improvements in the thermal stability of the $\mathrm{Pd} / \mathrm{SiC}$ interface. In all this, we are using techniques that could readily be incorporated into commercial processes. Moreover, as a result of our UHV approach to device fabrication, we are in a position to monitor and document each step of the process and to relate this data to device characteristics and performance.

At this stage of the device fabrication studies, we have shown that the $\mathrm{Pd} / \mathrm{SiC}$ interface is remarkably stable at temperatures up to $670{ }^{\circ} \mathrm{C}$. Experiments are now underway to study the effects of improved substrate surfaces on these interfaces. In addition, the other metal species will be investigated. These studies will form the major thrust of our device fabrication work in the next year.

Device modeling and electrical characterization studies were performed to complement these device fabrication studies. These included temperature dependent I-V and series resistance measurements. Presently $\mathrm{Pd} / \mathrm{SiC}$ structures produced in the above deposition experiments are being characterized.

In future electrical characterization studies, we intend to push the measurements to higher temperature and make measurements on device structures fabricated under a much wider range of process conditions. Moreover we will study the response of these device structures to temperature and several gases.

\section{REFERENCES}

1. Silicon Carbide Review paper

2. A.L. Spetz, P. Tobias, L, Unéus, H. Svenningstorp, L-G. Ekedahl, A. Göras, P. Rask, P. Salomonsson, P. Mårtensson, R. Wigren, P. Ljung, M. Mattsson, and I. Lundström, Proc. Transducers'99, Sendai, Japan, June 7-10, pp. 946-949, 1999.

3. L. Unéus, P. Ljung, M. Mattsson, P. Mårtenssson, R. Wigren, P. Tobias, I. Lundström, L-G. Ekedahl, and A. L. Spetz, Proc. Eurosensors XIII, The Hague, The Netherlands, September 12-15, pp. 521-524, 1999

4. G.W. Hunter, P.G. Neudeck, L.-Y. Chen, D. Knight, C.C. Liu, and Q.H. Wu, AIAA Paper 95-2647 (1995).

5. L.-Y. Chen, G.W. Hunter, P.G. Neudeck, G. Bansal, J.B. Pettit, D. Knight, C.C. Liu, and Q.H. Wu, Transactions of the Third International High Temperature Electronics Conference, Albuquerque, NM, June 9-14, 1996 Vol. 1 p x17.

6. Chen et al., J. Vac. Sci. Technol. A15 (1997) 1228

7. R.T. Tung, J.M. Poate, J.C. Bean, J.M. Gibson, and D.C. Jacobson, Thin Solid Films 93 (1982) 77-90.

8. K.C.R. Chiu, J.M. Poate, J.E. Rowe, and T.T. Sheng, Appl. Phys. Lett. 38 (1981) 988-990.

9. $\quad$ R.T. Tung, J.M. Gibson, and J.M. Poate, Phys. Rev. Lett. 50 (1983) 429.

10. R.T. Tung, J.M. Gibson, and J.M. Poate, Appl. Phys. Lett. 42 (1983) 888. 
11. W.A. Everson, D.W. Snyder, and V.D. Heydemann, Materials Science Forum 338-342 (1999) 837-840.

12. W.C. Mitchel, J. Brown, D. Buckanan, R. Bertke, K. Malalingham, F.D. Orazio, Jr., P.Pirouz, H-J.R. Tseng, U.B. Ramabadran, and B. Roughani, Materials Science Forum 338342 (1999) 841-844.

13. J.A. Powell and D. Larkin, Phys. Stat. Sol. B202 (1997) 529-548.

14. A.O. Evwaraye, S.R. Smith, M. Skowronski, and W.C. Mitchel, J. Appl. Phys. 74 (1993) 5269-5271.

15. D.B. Fenner, D.K. Biegelsen and R.D. Brigans, Journal of Applied Physics 66, (1989) 419.

16. L. Hirsch, Preparation of Substrates for Semiconductor Growth Using Atomic Hydrogen, Ph.D. Dissertation, Morgantown, WV: University of West Virginia (1998).

17. K.S. Ziemer, Studies of the Initial Stage of Silicon Carbide growth on Silicon, Ph.D. Dissertation, Morgantown, WV: University of West Virginia (1998).

18. V.M. Bermudez, Applications of Surface Science, 17 (1983) 12. 